\title{
GENEALOGY AND KNOWLEDGE-FIRST EPISTEMOLOGY: A MISMATCH?
}

\author{
By Matthieu Queloz iD
}

\begin{abstract}
This paper examines three reasons to think that Craig's genealogy of the concept of knowledge is incompatible with knowledge-first epistemology and finds that far from being incompatible with it, the genealogy lends succour to it. This reconciliation turns on two ideas. First, the genealogy is not history, but a dynamic model of needs. Secondly, by recognizing the continuity of Craig's genealogy with Williams's genealogy of truthfulness, we can see that while both genealogies start out from specific needs explaining what drives the development of certain concepts rather than others, they then factor in less specific needs which in reality do not come later at all, and which have also left their mark on these concepts. These genealogies thereby reveal widespread functional dynamics driving what I call the de-instrumentalization of concepts, the recognition of which adds to the plausibility of such instrumentalist approaches to concepts.
\end{abstract}

Keywords: genealogy, knowledge-first epistemology, models, instrumentalism, concept sharing, de-instrumentalization, E. J. Craig, Bernard Williams.

\section{INTRODUGTION}

What drives people to develop the concept of knowledge? This is the question which leads Craig (I990) to offer a genealogy of the concept of knowledge. Set in the state of nature, this genealogical narrative describes how the need for true beliefs would lead individuals to develop a primitive, prototypical form of the concept of knowledge as a tool by which to identify what, given the subject's needs and capacities, would be good informants. It then describes how the concept gradually loses this indexing to subjective needs and capacities to become more like our concept of knowledge.

The comparative neglect of this proposal is partially explained by the fact that it seems to be at odds with the currently influential knowledge-first epistemology (henceforth KFE) advocated by Timothy Williamson and others. KFE can be characterized here as involving two claims: (a) that knowledge is 
the most general factive stative attitude, ${ }^{1}$ an attitude one necessarily bears to a truth if one bears any other factive stative attitude to it; ${ }^{2}$ and (b) that the concept of knowledge is an unanalysable primitive that should act as a basis for explaining related concepts like believing, seeing or remembering. ${ }^{3}$

There are three reasons why one might think Craig's genealogy incompatible with KFE. The first is pointed out by Williamson himself. Applauding Craig's dismissal of the traditional programme of analysing the concept of knowledge into belief together with truth and some contested tertium quid, Williamson still considers Craig's project marred by its failure to acknowledge that the need for knowledge is prior to the need for true beliefs:

[Craig's project] remains too close to the traditional programme, for it takes as its starting point our need for true beliefs about our environment $[\ldots]$, as though this were somehow more basic than our need for knowledge of our environment. It is no reply that believing truly is as useful as knowing, for it is agreed that the starting point should be more specific than 'useful mental state'; why should it be specific in the manner of 'believing truly' rather than in that of 'knowing'? (Williamson 2000: $3 \mathrm{In} 3)^{4}$

Call this the wrong-starting-point problem.

The second reason is that Craig's original prototype of the concept of knowledge - proto-knowledge, as we might call it following Kusch (2009) - is a concept tracking 'proto-knowers' or good informants, and as Miranda Fricker highlights, Craig 'tends to describe the good informant as someone recognizable as having a true belief' (2007: $144 \mathrm{nI}$ ). But if a proto-knower is someone who, among other things, must have a true belief that $p$, this puts the concept of belief at the heart of the prototype of the concept of knowledge, and if this prototype is still part of our concept of knowledge, as Craig indeed claims (2007: I9I), this conflicts with one of the central tenets of KFE, that the concept of knowledge does precisely not involve the concept of belief. The problem, then, is that if Craig defines the good informant as someone who truly believes that $p$, this ultimately puts the concept of belief at the core of the concept of knowledge, 'and therefore depicts belief as prior to knowledge, so that knowledge is conceived as true belief plus a bit' (Fricker 2007: I44nI7). ${ }^{5}$ Call this the believing-as-the-core-of-proto-knowing problem.

Thirdly, and perhaps most importantly, KFE insists that the concept of knowledge is primitive and explanatorily fundamental (Williamson 2000: I85), but Craig's genealogy seeks to explain the concept of knowledge in terms of

\footnotetext{
${ }^{1}$ An attitude being factive if it is one that can only be borne to a truth, and stative if that attitude is a state.

${ }^{2}$ Williamson (2000: 48).

${ }^{3}$ Williamson (2000: 33,44, I85).

${ }^{4}$ See also Williamson (1995: 54I).

${ }^{5}$ Fricker goes on to remark that it would in principle be open to Craig to avoid this problem (2007: $144 \mathrm{nI}$ ). I shall argue for the stronger claim that this problem does not in fact arise in the first place.
} 
something more primitive - in particular, subjective needs for a concept that is more primitive than the concept of knowledge. This also seems incompatible with KFE, since, if the concept of knowledge is indeed fundamental in the way Williamson proposes, 'there is little space for any genealogy' (Kusch 201 : I2). ${ }^{6}$ Call this the no-room-for-genealogy problem.

In this paper, I argue that Craig's genealogy is compatible with KFE despite these three problems, and that, as Bernard Williams is reported to have believed, it even lends limited succour to KFE. ${ }^{7}$ The key to seeing this is to understand, first, that Craig's genealogy is not a historical account, but rather a dynamic model - a model with a time-axis - depicting the needs to which the concept of knowledge answers; and second, that the later part of Craig's genealogy factors in broader needs for what I call the de-instrumentalization of concepts which in reality do not come later at all, but are already at work alongside the needs the model starts out from. On this interpretation, the needs that are represented as coming later in the model are, if anything, more basic because more generic and more widely at work - they are the needs that explain why most concepts are shared and why, even if all concepts are tools, they are often not concept of tools. I argue that this becomes clear if we see the later parts of Craig's story as continuous with Williams's genealogy of truthfulness. As in Williams's genealogy, the idea is not that the concept of knowledge actually first emerged in its prototypical form and then developed into something else. Rather, the model represents as arising sequentially what in fact has to arise together: just as the most primitive form of truthfulness we should actually expect to find on Williams's view is already one that involves intrinsic valuing, so the most primitive form of the concept of knowledge we should actually expect to find is already nothing short of the objectivized concept we have, because what Craig's genealogy shows is that nothing short of that concept will do.

\section{MODELLING NEEDS}

Some groundwork is required before we can address the putative incompatibilities between Craig's genealogy and KFE. In particular, we must lay down an interpretation of what Craig's genealogy most basically is, namely a dynamic model of needs rather than a description of historical development.

\footnotetext{
${ }^{6}$ Kusch's own position is that this problem can be overcome: see Kusch (2009: 9o) and Kusch and McKenna (2018). I say more about this proposal below.

${ }^{7}$ Williams, who began unrelated lectures by recommending Craig's genealogy (Millgram 2009: I62n2I), took it to indicate that knowledge is prior to belief (Fricker 2007: II $3-4$ ng). Apart from influencing Craig, who was Williams's colleague at Cambridge, through his emphasis on the position of the inquirer (Williams I973), Williams himself sketched the beginnings of a genealogy of the concept of knowledge in his book on Descartes $(2005$, Ch. 2). Williams writes that he got the idea for a genealogy of the concept of knowledge 'from the Australian philosopher Dan Taylor, who may have been influenced in this direction by John Anderson' (Williams 2010: 215n4).
} 
The guiding idea of Craig's proposal is that instead of considering the concept of knowledge in isolation and trying to articulate an explicit intension that fits its intuitive extension, we should relate the concept to the practical needs it answers to, and understand it in terms of its point given those needs. In view of its rich history and the diversity of ways in which the concept has now come to be employed, however, its point may be difficult to read off our present practice of concept use. This is why Craig starts on his task using an idealized model of basic human needs in a simplified situation - what he dubs the 'state of nature'. The state of nature is thus best understood, not as our historical environment of evolutionary adaptation, but as a schematic representation modelling needs we can be presumed to have already in virtue of being human beings in the kinds of environments we live in. Craig is not concerned to describe the meanderings of the concept's actual historical development, but to string together a series of needs constituting a dynamic model explaining why, as a matter of near-inevitability, we were driven to develop the concept we have. It is because Craig starts out from such a model instead of directly attempting to discern the concept's point in the tangle of our actual conceptual practices that he can be said to offer a genealogy of the concept of knowledge. ${ }^{8}$ This genealogy is, in the first instance, an explanation of the structural origins rather than the datable historical origins of its target concept. If Craig offers a 'genetic account of the concept', it is, as he says, as a 'pragmatic account of its point' (I990: IO2). His genealogy is thus closer to reverse-engineering than to historiography.

So while there is a time-axis in Craig's model, this is because the initially strongly idealized model is gradually de-idealized by successively factoring in further practical pressures to which our actual concept responds - this is what turns the model into a dynamic model. However, the model's time-axis primarily stands, not for the passage of historical time, but for the stepwise approximation of the complexities of the present. ${ }^{9}$ The temporal order of the genealogical model is, at least in the first instance, merely the order in which the genealogist chooses to factor in those complexities. In a slogan: later = less idealized.

\section{STARTING POINTS AND THEIR PITFALLS}

With this interpretation in place, we turn to the worong-starting-point problem: that Craig begins his genealogy with the observation that 'human beings need

\footnotetext{
${ }^{8}$ It is only in Craig (2007) that he embraces the term 'genealogy' to describe Knowledge and the State of Nature.

${ }^{9}$ In developing this interpretation, I have particularly benefited from Kusch (2009, 20II, 2013), Kusch and McKenna (2018) and Fricker (2016), but see also Fricker (1998, 2007), Fricker (20I5), Gardiner (2015), Gelfert (20II, 20I4), Greco (2007), Hannon (2013), Henderson (201 I), Kappel (2010), McKenna (2014, 2015), Moore (1993), Pritchard (2012) and Reynolds (2017).
} 
true beliefs' (I990: I I) rather than with the need for knowledge. Does this vitiate the entire project from the perspective of KFE? I think not. Upon closer inspection, Craig's starting point turns out to be in principle neutral between belief-first and knowledge-first accounts.

The essential first move in Craig's genealogy is not its focus on the need for true beliefs, but its focus on the practical problem one faces in the situation of the inquirer. ${ }^{10}$ You will be in the situation of the inquirer if you are ignorant as to whether $p$ and need to find out, if you are to be successful in navigating your environment and satisfying even your most basic needs, whether $p$ whether, for example, the bear went into the cave. ${ }^{11}$ This means that we can preserve neutrality between belief-first and knowledge-first accounts without prejudice to Craig's account: we can say that human beings need truths about their environment, leaving it open whether the attitude they must bear to these truths is one of believing or knowing. Inquirers thus face a problem of the form: How to come by the truth as to whether $p$ ? This is all that Craig's genealogy requires to move forward, and it makes no difference whether this starting point is heard in a belief-first or in a knowledge-first key.

There is a worry one might have at this point: that it does make a difference whether the starting point is spelled out in knowledge-first terms or not, because if it is, the need to come by the truth as to whether $p$ will be the need to get into a state of knowing whether $p$, i.e. to get into a state of knowledge; and to presuppose the existence of knowledge in Craig's more or less declaredly pragmatist account of the emergence of the concept of knowledge is inconsistent. $^{12}$ It runs afoul of the pragmatist commitment to eschewing, whenever possible, the metaphysics-inviting strategy of explaining the concept of $\mathrm{X}$ in terms of the prior existence of $\mathrm{X}$. The pragmatist must, surely, put a ban on mentioning the object of the concept for purposes of explanation, and then try to explain how the concept would come about nonetheless, driven by forces that have nothing to do with being sensitive to its object. ${ }^{13}$

The simplest response for the pragmatist genealogist of knowledge is to concede that this is just one of those cases where the pragmatist ambition to explain $\mathrm{X}$ in terms of the concept of $\mathrm{X}$ without drawing on $X$ in any way reaches

\footnotetext{
${ }^{10}$ See Grimm (2015) for a supporting view.

${ }^{11}$ Craig's focus on the inquirer's situation is informed by Williams (I973: 146), who sees a déformation professionnelle in philosophers' tendency to start from the perspective of the examiner rather than the inquirer. For Williams, the standard situation with regard to knowledge is not one in which I assess whether someone knows something already known to me ('Does $A$ know that $p$ ?'); it is that in which I seek someone who knows what I do not yet know ('Who knows whether $\left.p ?^{\prime}\right)$.

12 Craig describes his method as 'conceptual' or 'pragmatic synthesis' or 'practical explication' (I990: 8, I4I). In his Wittgenstein lectures in Bayreuth, he speaks of his 'pragmatic method' (I993: 44). Thanks to an anonymous reviewer for pressing me on this point.

${ }^{13}$ See Blackburn (2013: 7I; 20I7) as well as the essays in Misak (2007), particularly Price and Macarthur (2007: 95) and M. Williams (2013: 128).
} 
its limits, and that this is no surprise if, as KFE suggests, knowledge is thought of as fundamental to having a mind at all. Accepting mental states of knowing as parts of one's ontology hardly seems outrageously metaphysical, and we can still usefully imagine a community lacking the concept of knowledge even within KFE, where the idea of imagining a human community in which there is no knowledge 'is probably not intelligible', because 'human beings always have perception and other automatic ways of knowing that it would be hard to imagine us ... lacking for any significant length of time' (Reynolds 20i7: I2). ${ }^{14}$ It is true that we could not grasp what it would mean for a creature to have knowledge if we did not also grasp the concept of knowledge - it would not be intelligible to us as knowledge, but it does not follow that knowledge cannot exist without the concept of knowledge. Consequently, there is room for us to contemplate a situation in which agents have knowledge, but lack the concept thereof, so long as we possess the concept of knowledge that allows us to conceptualize the situation in this way; and we can illuminatingly do this as long as the practical contribution of the concept differs from the practical contribution of its object. This response retains the compatibility of Craig's genealogy with KFE while conceding that its strategy is characteristic of pragmatism only up to a point: it is a pragmatic genealogy rather than a primarily historical genealogy because it focuses on conceptual practices and their points given practical needs.

But there are two further things one might say. One is to highlight that Craig's genealogy perhaps does not run afoul of pragmatist principles after all: even on the KFE-friendly reading, Craig does not start by asking what knowledge is, or what 'knowledge' refers to; in good pragmatist fashion, he starts with agents and the practical needs that would give the concept of knowledge a point. Moreover, as Blackburn (2017) shows, it is by no means clear what exactly the pragmatist ban on mentioning certain entities in your explanations amounts to. Craig would clearly run afoul of pragmatist principles if he said that we think in terms of knowledge because there is so much knowledge aroundthat is, to put it slightly more carefully, if his explanation had the following form:

There is $\mathrm{X}$.

We need to be suitably sensitive to the presence of $\mathrm{X}$.

Therefore, we develop the concept of $\mathrm{X}$ for this purpose.

But Craig's explicitly rejects a strategy along these lines (i990: 3), and this is where he proves himself a pragmatist after all. It is not the objectknowledge - that attracts the use of the concept of knowledge. It is the agent's needs that drive the emergence of the concept by which the object, knowledge,

\footnotetext{
${ }^{14}$ See Williamson (2000: $\left.46-7\right)$.
} 
can then be delineated. In other terms, Craig's genealogy is subtler and more informative than the above schema because the need to be sensitive to the presence of knowledge is his explanandum rather than his explanans. ${ }^{15} \mathrm{He}$ derives this need from other needs instead of assuming it.

The other response is to shift from the defensive into what seems a selfdefeating strategy but really brings out what makes imaginary genealogies so useful in dealing with fundamental concepts: that they allow us to consider as arising separately what in fact has to arise together. We can then grant that if the concept of knowledge is as central to our lives as KFE makes out, any state-of-nature scenario will soon covertly presuppose, not just the existence of knowledge, but even the existence of the concept thereof. Given KFE, any actual community that lacked the concept of knowledge would also have to lack a host of further concepts and practices that depend on the concept of knowledge, such as the practice of telling someone that $p$ (governed by the norm that one must know that $p$ ), or even the concepts of seeing or remembering that $p-\mathrm{a}$ point that Reynolds (20I7) grants and Elizabeth Fricker (2015) presses more critically. Reynolds' solution is to imagine a community deploying variants of the concepts of seeing or remembering that do not depend on the concept of knowledge - seeing* and remembering*, which can be used to report appearances without entailing attributions of knowledge (20I7: $3 \mathrm{I}-4)$. In principle at least, one could do this across the board until one had eradicated all traces of the concept of knowledge in the initial stage of one's model.

But perhaps what matters is not that we do replace all affected conceptual practices with unconnected variants in our model, but that we could do so without losing the genealogy's explanatory force - perhaps, just because the genealogy is a model which, like other models, idealizes and sometimes distorts reality, we can instructively treat as independent what is in fact conceptually related. The point of doing so is to identify some of the salient needs driving concept-users to develop the concept and to offer a perspicuous representation of key aspects of that concept's practical contribution to our lives. KFE claims for the concept of knowledge a status that many philosophers are already willing to grant the concept of truth, for example, namely that it is so fundamental that we struggle to imagine language-using human societies without already covertly drawing on it. But why should the mere fact that the concept of truth is fundamental in this way bar us from using state-of-nature fictions to help us identify some of the functions that the concept of truth performs? As Fricker emphasizes following Bernard Williams, it is precisely the 'genius of using the state-of-nature format in the arena of epistemology' that it allows one 'to tell a narrative story about X (e.g. the concept 'know') even where

\footnotetext{
${ }^{15}$ I leave aside here the question whether knowledge's being a social or a natural kind makes any difference to the compatibility of KFE with Craigean genealogy. I agree with Kusch (2013) and Kusch and McKenna (2018) that it does not.
} 
we find it otherwise barely intelligible that there could have been a narrative development towards X', for instance because 'the idea of a progression towards $\mathrm{X}$ is conceptually impossible' (Fricker 1998: $\mathrm{I} 65$ ). ${ }^{16}$ The fact that a concept is so fundamental as to be involved in many basic human activities only means that we would do well not to think that one simple state-of-nature story will exhaust that concept's practical contribution across the entire range of our conceptual practices. The question, then, is not whether the concept explained by a genealogy was covertly presupposed in it - if the concept is fundamental enough, it very likely was - but whether it was presupposed in a way that renders the explanation uninteresting. And as long as the explanation uncovers instrumental relations between the concept and certain needs that we were not aware of before, the explanation will retain its interest.

Even by pragmatist lights, then, Craig can illuminatingly ask what would drive a community of inquirers who need to know whether $p$ to develop the concept of knowledge - even if this concept is internally related to many other basic human activities, and even on the assumption that this presupposes the existence of states of knowledge. The former is no problem because the genealogy is imaginary, and can, in virtue of this, help us identify some of the salient ways in which the concept serves our needs; and the latter is no problem because the genealogy does not presuppose the need to be sensitive to the presence of knowledge, but rather, as we shall see in detail in the next two sections, illuminatingly derives this need from other needs.

\section{WHAT INFORMANTS NEED TO BE}

Let us now turn to the believing-as-the-core-of-proto-knowing problem: that if the good informant must be someone who truly believes that $p$, this puts the concept of belief at the core of the concept of proto-knowledge, and consequently also at the core of the concept of knowledge. I argue in this section that upon closer inspection, this problem does not arise, and that Craig's account can even be read as lending succour to KFE.

To see why, we need to delve further into Craig's genealogy. Given inquirers' need to find out the truth as to whether $p$, they can make some headway by relying solely on perception, reasoning, and memory - their 'on-board' resources (Craig i990: ir). Yet the mere fact that inquirers are not all in the same place at the same time entails that there are pressures on inquirers to engage in cooperation to find things out. Hence, inquirers have a need for good informants as to whether $p$. In characterizing good informants, Craig also tends to take his lead from the programme of conceptual analysis when he notes

\footnotetext{
${ }^{16}$ A point originally made by Williams in a lecture entitled 'Truth and Truthfulness', delivered to The London Consortium, Birkbeck College, London, May 1997 (Fricker 1998: 165nı3).
} 
that they typically are individuals who truly believe that $p$ and who also display further properties that render them suitable as informants (I990: I2-I5, 96). But the characteristics of good informants that are central to his account are those that are practically relevant to the inquirer's success. From this pragmatic perspective, the requirements on good informants are that they should be (i) as likely to be right as to whether $p$ as is necessary for the inquirer's purposes; ${ }^{17}$ (ii) accessible to the inquirer here and now; (iii) intelligible to the inquirer; (iv) honest, in the most basic sense of being open with the inquirer; and (v) such that, for whatever reason, the inquirer finds their testimony convincing.

But if inquirers need good informants, they need to be able to recognize them as such. This entails that informants need to be identifiable as satisfying some or all of the above conditions through 'indicator properties': standing in the right causal relation to the state of affairs in question, for instance, or having proven reliable in the past, or being able to offer justifications. Moreover, it entails that inquirers need a concept of the good informant whose application tracks such indicator properties.

It is here that the prototypical form of the concept of knowledge-protoknowledge - makes its appearance: it arises in answer to the need for a concept of someone who is a good informant whether $p$, given the needs and capacities of the inquirer here and now. A good informant in this sense is someone who proto-knows whether $p$. Note that proto-knowledge is still markedly different from our concept of knowledge. It is strongly perspectival, i.e. indexed to the particular inquirer's needs and capacities at that time and place: a protoknower is someone who will suit my needs, given my capacities, here and now. Moreover, the concept is what we may call purely instrumental: a concept is purely instrumental just in case (a) the concept is instrumental in serving the conceptuser's needs; and (b) the concept is the concept of something instrumental in serving the concept-user's needs. The status of being a proto-knower is so closely tied to my needs that there is no conceptual room for a proto-knower who, for whatever reason, is no use to me.

We can now see that the believing-as-the-core-of-proto-knowing problem evaporates under analysis. The heart of Craig's proposal is the inquirer's need for proto-knowers in the sense of good informants. Yet what the inquirer has a need for, given the inquirer's need to find out the truth as to whether $p$, is not someone who has a true belief as to whether $p$, but someone who proto-knows whether $p$, and on Craig's account, believing that $p$ is not a necessary condition on proto-knowing that $p$ : 'if the informant satisfies any condition which correlates well - as we believe - with telling the truth about $p$, he will be regarded

\footnotetext{
${ }^{17}$ Some think that the focus should lie not so much on the probability of being right as on the possibility of error. See Pritchard (2012) for a reconstruction of Craig's genealogy in these terms which highlights how, in the state of nature, the salient error-possibilities would be restricted to live and actual ones, while our concept of knowledge plausibly also covers potential error-possibilities.
} 
as a good source' (Craig I990: I3). The condition in which the informant herself believes that $p$ is - however typical - only a special case of this; other circumstances concurring, the informant may not need to believe what she says, and even a very diffidently offered piece of information may come to be accepted by the inquirer. It is simply more likely that an informant who believes that $p$ will come out with $p$ and will do so in a manner capable of persuading the inquirer. But from a pragmatic point of view, what really matters is that the informant be likely enough to be right, accessible, intelligible, and willing to say whether $p$ in a manner capable of persuading the inquirer.

\section{A GENEALOGY SHOWING THERE TO BE NO ROOM FOR GENEALOGY}

This leaves us with the no-room-for-genealogy problem: if the concept of knowledge is primitive and explanatorily basic in the way Williamson suggests (2000: I85), this may be thought to exclude any genealogical development towards it. Craig's aspiration to understand the concept of knowledge in terms of an explanatorily more basic prototype consequently seems incompatible with KFE.

Again, compatibility with KFE can be secured relatively easily: Craig can in principle grant that the concept of knowledge we now have acts as an unanalysable basis in the explication of other concepts like seeing and remembering. But this does not bar the concept of knowledge from having developed out of the concept of proto-knowledge. We must distinguish logical from genealogical priority. The concept of knowledge may be logically prior without being genealogically prior. Even if the concept of knowledge does not factorize as conceptual analysis requires, we can still reflect on its conceptual synthesis - on why we might have come to develop the concept and on the practical pressures that gave it the shape it now has. While the concept of knowledge may now hold a fundamental place within our conceptual scheme in a way that precludes its factorization into logically prior constituents, this does not in principle exclude its having developed out of genealogically prior predecessors. ${ }^{18}$ Moreover, it is even compatible with KFE that these predecessors would have been factorizable into constituents.

Yet I want to suggest that Craig's genealogy has more than mere compatibility to offer KFE: it provides explanatory support for the claim that the concept of knowledge is primitive. Even among interpreters of Craig who are sympathetic to KFE, this is not a claim one often finds. Kusch and McKenna (2018), for example, argue that Craig's genealogy undercuts the claim that the concept of knowledge is primitive: by taking the failure of traditional analyses

\footnotetext{
${ }^{18}$ A point noted also by Kusch (2009: 90).
} 
of the concept of knowledge to motivate a pragmatic genealogical approach to it, Craig's genealogy undercuts a crucial motivation for KFE, for Williamson takes that same failure to motivate the claim that the concept of knowledge is primitive. But I do not think we need to see these motivations as competing with each other; on the contrary, if the concept of knowledge is taken to be primitive, that just renders all the more pressing the question why this primitive notion should have been found useful, since its utility cannot then be explained in terms of the individual utility of its conceptual components. And this is precisely the question that Craig's genealogy answers: it presents the concept of knowledge as practically basic and explains why we should expect any human society to operate with something very like the concept of knowledge rather than with the concept of the good informant, because nothing short of the concept of knowledge will do.

I want to suggest, then, that Craig's genealogy gives us reason to think that the concept of knowledge did not in fact have much in the way of historical predecessors, but predominantly existed in something like its present form. This means that there is an important sense in which Craig vindicates the idea we associated with KFE, that there is little room for a genealogy of the concept of knowledge that does not yet involve the full-fledged concept. There remains plenty of room for genealogy downstream of the emergence of the concept of knowledge, of course. But if Craig is right, there is hardly much room upstream of it. Nothing in Craig's genealogy excludes that we can write informative histories of how the concept of knowledge went on to develop under various socio-historical circumstances. What it suggests is that any such history will likely already start with something very like the generic concept of knowledge that Craig ends up with in Knoweledge and the State of Nature. Far from showing that Craig's genealogy is incompatible with $\mathrm{KFE}$, the no-room-for-genealogy problem thus points us to another respect in which the genealogy ends up buttressing KFE.

The difficulty of seeing this arises from the fact that in a seeming paradox, Craig uses genealogy to show that there is no room for genealogy. But the air of paradox disappears once we view Craig as using an imaginary genealogy to show that we should not expect there to be much room for a historical genealogy: he constructs a model highlighting practical pressures that lead us to expect always already to find the concept of knowledge. The key to seeing this is to recognize that the later part of Craig's genealogy factors in broader needs which in reality do not come later at all, but are already at work alongside the needs the model starts out from. The development depicted in the genealogical story corresponds to the de-idealization of the model achieved by factoring in less specific needs - needs that are not specific to the practical challenges explaining the emergence of the concept of knowledge. But because these less specific needs must in reality be at work from the start, the endpoint of Craig's genealogy must in reality be the most primitive serviceable form of the concept of knowledge. 
This becomes particularly clear once we see the formal commonalities and continuities between Craig's genealogy and Bernard Williams's genealogy of truthfulness. ${ }^{19}$ There are also substantive commonalities and continuities here, since Williams mirrors Craig's procedure to explain something Craig takes as given, namely the willingness of informants to be truthful. But the formal points of comparison are more interesting for our purposes, because they render salient the contours of Craig's genealogy and indicate how, taken together, these two genealogies yield a powerful instrumentalist framework in which to make sense of concepts as tools or techniques serving the practical needs of concept-users. ${ }^{20}$

First, in both genealogies, later means less idealized: the developments that take place in the state of nature actually correspond to the gradual deidealization of a model through the factoring in of further needs. The models thereby take into account the interplay between, on the one hand, the functional dynamics that specifically give rise to the concepts they are concerned with, and, on the other hand, less specific functional dynamics that shape many other concepts as well.

Secondly, the less specific functional dynamics which the two genealogists focus on are continuous with one another: the two genealogists can be understood as describing different phases on an axis of de-instrumentalization. At the axis' point of origin lies the thoroughly subjectivized and instrumentalized concept indexed to the needs and capacities of the concept-user. At the axis' middle point lies the objectivized but still instrumentalized concept which, while public and no longer indexed to the individual concept-user's needs, is still the concept of something instrumental to need-satisfaction and in this sense indexed to a generic subject's needs. At the axis' endpoint, finally, lies the objectivized and de-instrumentalized concept that is no longer indexed to anyone's needs, because it is no longer the concept of something instrumental to need-satisfaction, but of something intrinsically valuable, i.e. of something that is valued for its own sake.

Using this model of an axis of de-instrumentalization, we can see that Williams continues where Craig leaves off. Craig describes the dynamics driving the development from the point of origin to the middle point, thereby showing why, even if we approach concepts as tools originating in the individual conceptuser's needs, we should expect many of them to become objectivized due to the instrumental value of objectivized instrumental thought. Williams's genealogy then describes the dynamics driving the development from the middle point to the endpoint. He shows why, on the same approach, we should expect some of our

\footnotetext{
${ }^{19}$ There are important differences between the genealogies as well, such as the greater role Williams allocates to historically localised developments. I say more about these in Queloz (2017, 2018a, 2018b, Manuscript).

${ }^{20}$ See Brandom (201I) for an overview of this instrumentalist tradition and its roots in the work of Wittgenstein and Rorty.
} 
concepts to become de-instrumentalized altogether due to the instrumental value of non-instrumental thought. To sharpen this idea, we need to distinguish between thought couched in instrumental terms and thought that is instrumental to the satisfaction of needs, whatever terms it is couched in. Thinking in instrumental terms is often instrumental to the satisfaction of one's needs; but what Williams brings out is that sometimes, non-instrumental thought is, not just the better instrument, but the only instrument that is up to the task. There are circumstances under which it is only by being bloody-minded rather than benefit-minded that one can reap benefits - notably, when a concept needs to throw new reasons for actions into the balance in order to make a practical difference: as long as truthfulness is conceived of in merely instrumental terms, it will be too vulnerable to free-riders to make a difference-people will conform when it is anyway in their interest, and defect otherwise; it is only if truthfulness is thought of as possessing more than merely instrumental value that a stable practice can form and yield practical benefits for those who engage in them. ${ }^{21}$ Consequently, nothing short of the intrinsic valuing of truthfulness will do, and the most primitive form of truthfulness we should actually expect to find is already one that involves intrinsic valuing.

This leads us to the third formal point of comparison, which is the one that is crucial to seeing how Craig's genealogy lends explanatory support to KFE's claim that the concept of knowledge is primitive. The upshot of Williams's genealogy is not that, in real history, truthfulness first arose in purely instrumental form, and only later acquired intrinsic value by coming to be regarded as a virtue. Rather, the model shows that truthfulness could only have been stable and made a difference insofar as it was already valued intrinsically. Similarly, the upshot of Craig's genealogy is not that the concept of knowledge actually first emerged in its prototypical form and then developed into something else. Rather, the model represents as arising sequentially what in fact has to arise together, and just as the most primitive form of truthfulness we should actually expect to find is already one that involves intrinsic valuing, so the most primitive form of the concept of knowledge we should actually expect to find is already nothing short of the objectivized concept we have. The genealogies of Craig and Williams thus have the following formal commonality: they both tell us that if $\mathrm{X}$ were to arise, it would, due to the combination of certain practical pressures, likely be driven to develop into Y. This does not carry the implication that $\mathrm{X}$ in fact ever existed; on the contrary, it helps explain why we find $\mathrm{Y}$ rather than $\mathrm{X}$, because it shows why, if $\mathrm{X}$ ever existed, it would soon have turned into $\mathrm{Y}$.

${ }^{21}$ See Williams (2002: 59) and Craig (2007: 198-200). The practical requirement is only that truthfulness be valued intrinsically. Whether, under the right circumstances, this is sufficient for them to be intrinsically valuable is then a further question, which Williams answers in the affirmative (2002: 92), and which I discuss in Queloz (2018b). 
This is key to understanding the second part of Craig's genealogy, which aims to explain why we deploy the concept of knowledge rather than the concept of proto-knowledge, and why, if the latter ever existed, it would soon have turned into the former. It is to this end that Craig invokes the pressure towards objectivization. Our concept of knowledge picks out more than just good informants - someone might know something without being inclined or even able to pass on the information to me. Someone could be useless as a good informant, and thus fail to qualify as a proto-knower, while still qualifying as a knower according to the concept of knowledge we actually have (Luigi knows where he buried Mario's body, but he is not telling). ${ }^{22}$ In contrast to the concept of proto-knowledge, our concept of knowledge does not essentially involve the notion of subservience to practical needs.

Craig accounts for this difference by taking into account less specific functional dynamics which would drive the objectivization of the concept of protoknowledge and issue in something like our concept of knowledge: the more concept-users resemble social and cooperative creatures with different needs and capacities, the more there are practical pressures on their concepts to emancipate themselves from their practical origins as private tools answering individual concept-users' needs. ${ }^{23}$ Were it not for objectivization, concepts would be thoroughly indexed to the needs and capacities of specific agents. In virtue of objectivization, this indexation is weakened and the concepts are less perspectival. They are driven to develop into more objectivized concepts that are less indexed to particular perspectives.

To understand the pressures driving subjectivist thought towards more objectivized thought, we need to understand what drives the emergence of capacities to distinguish between invariable, objective properties of things that render them suitable to certain uses on the one hand, and variable, subjective needs and capacities that incite and enable individuals to use them on the other. Consider a primitive form of concept-mongering that lacks such distinctions. At this primitive stage, I only have a need and am in want of something which will satisfy it, there and then. The conceptual capacity I will then minimally require is that of distinguishing holistically between situations that can satisfy the need and situations that cannot. I will thus wield a thoroughly subjectivized concept picking out whatever can satisfy my present needs, given my current capacities, here and now. Yet all but the simplest of organisms will be driven beyond this primitive holism, because I shall be able to exploit many more of the opportunities that the environment affords if I am capable of making more fine-grained distinctions. There are practical pressures on me to distinguish whatever can satisfy my present needs, given my current capacities, here,

\footnotetext{
${ }^{22}$ Craig (1990: 17, 82).

${ }^{23}$ Craig (I993: 90). My exposition of the process of objectivization is based on Craig (I990: 82-97) and Craig (I993: 8I-II5).
} 
now, from whatever can do so later; or somewhere else; or given capacities I anticipate developing (my energy-reserves are now depleted, but I will soon recover); or given needs I anticipate having (I may not be hungry now, but will soon need food again). I am thus driven to discriminate between these and many more different aspects of opportunity-affording situations and thereby become sensitive to new opportunities afforded by situations I do not currently occupy, but which I might come to occupy. If I am a social and cooperative creature, additional advantages will come with sensitivity to opportunity-affording situations that I cannot myself occupy - those available given someone else's capacities, such as Mum's, for example, or given the needs of someone else, whom I might direct towards that opportunity in the hope of reciprocation. I will likewise be interested in the directions others can give me, and with that interest comes the interest in their operating concepts that are detached from their perspective - just as they have an interest in my being able to abstract from my needs and capacities when directing them. ${ }^{24}$ Even if I plan to free-ride, I need to appreciate their points of view in order to make effective use of them. At the end of this process lie shared concepts which abstract from the difference between concept-users. They track the objective properties of things that render them suitable to certain uses, irrespective of whether anyone in particular has the need or capacity to use them. Private thinking tools have turned into public ones.

In line with the interpretation I want to defend here, Craig notes that this genealogy "need not presuppose that the wholly egocentric, "subjectivized" thought from which it began actually exists or existed'; his 'argument is only that if it exists, at any time, or in any individual, it will develop in the direction of objectivization', and therefore 'there will be objectivized concepts, whether things started that way or not' (I990: 84). When applied to the concept of protoknowledge, the process of objectivization similarly leads to the emancipation of the concept from the needs of the individual concept-user. If a group of social and cooperative humans individually started with the subjectivist concept of the good informant (for themselves, here, now, given their current needs and capacities), they would likewise be driven to distinguish between the objective grounds of suitability as informants and the subjective needs and capacities to make use of them. Milestones in that process of objectivization are: (i) selfascription, as individuals come to scrutinize their own qualifications in answer to the question 'Who knows whether $p$ ?'; (ii) the direction of third parties to people who might be good informants for them, given their needs and capacities (which means that the more different inquirers an informant is to be suitable for, the more demanding the role of the informant becomes - at the limit, the informant has to be suitable to whomever is asking, whatever their purpose); (iii) the reliance on the identification of good informants by third parties in addition to the reliance on indicator properties visible to oneself; (iv)

${ }^{24}$ Craig (1990: 83-4). 
group ventures in which individuals need not care about whether they know whether $p$ as long as someone in the group knows. ${ }^{25}$

These developments progressively weaken proto-knowledge's indexation to any given perspective and issue in something that is at least close to knowledge: the concept of someone who has a sufficient probability of being right about whether $p$ for anyone's purposes, independently of the needs and capacities of any particular inquirer (if the standard for counting as a knower varied wildly from one perspective to the next, knowledge attributions would too rarely be such as to allow others to rely on them for a variety of purposes) ${ }^{26}$ who may or may not be honest, accessible or intelligible to any particular inquirer; and who may or may not be straightforwardly identifiable for any particular inquirer as satisfying these criteria. Craig concludes that ' $[\mathrm{t}]$ he concept of knowing ... lies at the objectivized end of the process; we can explain why there is such an end, and why it should be found worth marking in language' (I990: 90-I).

Even if the concept of knowledge did not in fact have much by the way of historical predecessors, therefore, Craig's genealogy helps explain why this is so: given the practical exigencies highlighted by the dynamic model of the process of objectivization, nothing short of the concept of knowledge - or at least something very like it - will do. This supports KFE's contention that the concept of knowledge is basic: it shows it to be practically basic in that any human society would find it hard to get by without it. We are social and cooperative agents who have a need for truths; hence a need for informants; hence a need to identify who proto-knows whether $p$; hence a need for the concept of proto-knowledge; hence a need for an objectivized form of the concept of proto-knowledge; hence a need for the concept of knowledge. Only the latter forms an apt response to the combination of needs which Craig derives from uncontroversial facts about generic social and cooperative inquirers. If Craig is right, this makes it indeed unlikely that there should have been a gradual historical development towards the concept of knowledge.

Finally, recognizing the continuity in the dynamics of de-instrumentalization described by Craig and Williams indicates how Craig's genealogy might be pushed further: it suggests that the narrative could be expanded to include the transformation of the concept of proto-knowledge from a concept of something purely instrumental to a concept of something possessing more than purely instrumental value - from a concept at the middle to one at endpoint of the axis of de-instrumentalization. ${ }^{27}$ This is because part of what makes informants good informants is that they are disposed to be truthful, i.e. accurate and sincere; but if Williams is right, there are instrumental reasons why the notion of

\footnotetext{
${ }^{25}$ See also Fricker (2010: 40), Kusch (2011: 9-10), Hannon (2013: 905-6) and E. Fricker (2015) for valuable overviews of Craig's process of objectivisation.

${ }^{26}$ See Williamson (2005: IOI) and Hannon (2013: 916). For helpful discussions of these pressures towards higher standards, see Henderson and Horgan (2015), Grimm (2015) and McGrath (2015).

${ }^{27}$ See also Kusch (2009: 74-6).
} 
goodness encapsulated in the concept of the good informant cannot remain simply of the kind involved in being a good knife - the goodness of a tool suited to its purpose. Rather, the concept of the good informant, and thus of proto-knowledge, needs to involve intrinsic valuation in order to sustain the institution of information pooling that gives the concept its point. Insofar as our concept of knowledge can be understood as a de-instrumentalized version of the concept of the good informant, and insofar as the practical exigencies driving this de-instrumentalization include a need for the concept to involve the notion of intrinsically valuable epistemic virtues, this might be hoped to help us explain why the concept of knowledge has been tied to intrinsic goodness or virtuous performance. This points to how Craig's genealogy might connect to discussions over why knowledge seems superior in value to true belief, and why achieving knowledge has been thought to involve the exercise of virtue. ${ }^{28}$ Perhaps, once combined with KFE, the genealogy of the concept of knowledge might also establish explanatory connections to other research programmes such as virtue epistemology. ${ }^{29}$

\section{GONGLUSION}

To sum up: I have examined three reasons to think that Craig's genealogy of the concept of knowledge is incompatible with KFE, and found that far from being incompatible with it, Craig's genealogy lends succour to it. By recognizing the commonalities and continuities of Craig's genealogy with Williams's genealogy of truthfulness, we can see that while both genealogies start out from specific needs, they then factor in less specific needs which in reality do not come later at all. These genealogies thereby reveal widespread functional dynamics driving what I called the de-instrumentalization of concepts.

Once we recognize the deep continuity between Craig's process of objectivization and the process that Williams describes in his genealogical account, the works of these two genealogists can be seen as two complementary and mutually supportive instrumentalist explorations of the functional dynamics driving the de-instrumentalization of concepts. In particular, they add to the plausibility of the instrumentalist approach that they exemplify by showing how it can overcome two major hurdles. One is that if we approach concepts as tools originating in the individual concept-user's needs, we should expect most of them to remain closely tied to the individual subject's need and capacities. Yet this is not what we find. The other hurdle is that a purely instrumental (2012)

${ }^{28}$ See Greco (2003), Kvanvig (2003), Sosa (2007), Kusch (2009), Fricker (2009) and Pritchard

${ }^{29}$ See Gardiner (2015) for a valuable discussion of why Craigean genealogy should be integrated into a pluralistic methodological canon. See also Henderson and Horgan (2015) for its promise in dealing with evaluative concepts. 
view of human thought seems to ignore the fact that we do not view the world in purely instrumental terms.

On the interpretation I have given, Craig removes one hurdle by showing that there are instrumental reasons why concepts come to assume a form that belies their practical origins in the needs of individuals. The needs of the individual concept-user are better served by objectivized concepts which are not indexed to those needs. Hence, the subservience of concepts to the needs of the individual concept-user tends to efface itself for instrumental reasons. By identifying these reasons, Craig provides a blueprint for an explanation of why concepts tend to be shared or public..$^{30}$ This is a matter of fact admitting of explanation. Craig's explanation is that because human life is social and cooperative, and because human concept-users differ in their needs and capacities, there are pressures on concept-users to operate with concepts that pick out what remains constant across concept-users' perspectives. This is not an all-or-nothing matter, as we can make sense of partial differences between perspectives. Some of our concepts may be more tinged with subjectivity than others. Concepts in the natural sciences tend to be more objectivized than those in judgements of taste, for example. But the main point is that Craig offers a framework in which to think about why a particular concept has been objectivized to the particular extent that it has. Once we start thinking of degrees of objectivization as responses to practical demands, we can reflect on the pressures driving a concept to reach just the degree of objectivization it displays. We can ask what the point is of deploying a concept that is objectivized to this degree. In legal contexts, having concepts that are strongly objectivized serves a point, since much depends on our ability to ensure that what is an instance of a concept for one person is also an instance of it for another person (think of the efforts that went into objectivizing the concept contract). In the context of choosing a wine, by contrast, oenological concepts better serve their point if they are indexed to the drinker's needs and capacities: my idea of a buttery and crisp but balanced white wine is not yours, nor would it do you much good if it were. ${ }^{31}$

The other hurdle for instrumentalism about concepts is dealt with by Williams's insight into the instrumentality of non-instrumental thought: some concepts can only serve as tools if they are not concepts of tools, but of things valued for their own sake. This explains why some concepts are driven even further down the axis of de-instrumentalization. By giving instrumentalist approaches to concepts a genealogical dimension, Craig and Williams make room for dynamic models allowing us to grasp the practical origins of concepts while also understanding why these concepts shed the traces of their

\footnotetext{
${ }^{30}$ See Glock (2009, 2010) and Prinz (2002: I4-6, I53).

${ }^{31}$ See Gardiner (20I5) for a related discussion of the pressures driving concepts towards precision or vagueness.
} 
instrumental origins. This paves the way for a flexible and non-reductive instrumentalism about concepts which will gain in explanatory power as we understand more about what our needs are and how they have changed in the course of history.

Perhaps the chief lacuna in that framework as these two genealogists have left it arises from their tendency to focus on generic human needs - needs we all share, on any understanding of the scope of 'we'. Yet it would be naive to think that all concepts serve everyone's needs. Concepts might earn their keep by serving the few at the expense of the many. Moreover, needs change, not least through the acquisition of new concepts. To increase the explanatory reach of the instrumentalist approach even further, these complications need to be addressed and incorporated. But this is a task for another occasion. ${ }^{32}$

\section{REFERENCES}

Blackburn, S. (2013) 'Pragmatism: All or Some?', in H. Price (ed) Expressivism, Pragmatism and Representationalism, 67-84. Cambridge: GUP.

(2017) 'Pragmatism: All or Some or All and Some?', in C. Misak and H. Price (eds) The Practical Turn: Pragmatism in Britain in the Long Twentieth Century, 6I-74. Oxford: OUP.

Brandom, R. (201 I) 'Vocabularies of Pragmatism: Synthesizing Naturalism and Historicism', Perspectives on Pragmatism: Classical, Recent, and Contemporary, i 6-57. Cambridge, MA: Harvard University Press.

Craig, E. (1990) Knowledge and the State of Nature: An Essay in Conceptual Synthesis. Oxford: Clarendon Press.

_ (1993) Was wir wissen können: Pragmatische Untersuchungen zum Wissensbegriff. WittgensteinVorlesungen der Universität Bayreuth. Frankfurt am Main: Suhrkamp.

_ (2007) 'Genealogies and the State of Nature', in A. Thomas (ed) Bernard Williams, I8I-200. Cambridge: CUP.

Fricker, E. (2015) 'Know First, Tell Later: The Truth about Craig on Knowledge', in J. Greco and D. Henderson (eds) Epistemic Evaluation: Purposeful Epistemology, 46-86. Oxford: OUP.

Fricker, M. (1998) 'Rational Authority and Social Power: Towards a Truly Social Epistemology', Proc Aristotelian Soc, 98/2, I59-77.

_ (2007) Epistemic Injustice: Power and the Ethics of Knowing. Oxford and New York: OUP.

_ (2009) 'The Value of Knowledge and The Test of Time', Roy Inst Philos Suppl, 64, I2 I-38.

(2010) 'Scepticism and the Genealogy of Knowledge: Situating Epistemology in Time', in

A. Haddock, A. Millar and D. Pritchard (eds) Social Epistemology, 51-68. Oxford: OUP.

(2016) 'What's the Point of Blame? A Paradigm Based Explanation', Noûs, 50/ I, I65-83.

Gardiner, G. (2015) 'Teleologies and the Methodology of Epistemology', in J. Greco and D. Henderson (eds) Epistemic Evaluation: Purposeful Epistemology, 31-45. Oxford: OUP.

Gelfert, A. (201 I) 'Steps to an Ecology of Knowledge: Continuity and Change in the Genealogy of Knowledge', Episteme, 8, 67-82.

(2014) A Critical Introduction to Testimony. London: Bloomsbury Academic.

Glock, H.-J. (2009) 'Concepts: Where Subjectivism Goes Wrong', Philosophy, 84/1, 5-29.

${ }^{32}$ I would like to thank Markus Wild, Martin Kusch, Robin McKenna, Michael O'Leary, Rebekka Hufendiek, Anne Meylan, Muriel Leuenberger and Damian Cueni for valuable discussions of these issues. Thanks are also due to two anonymous reviewers for The Philosophical Quarterly for their extremely helpful comments. This work was supported by grant $\mathrm{N}^{\circ}$ PoBSPI_I62025 of the Swiss National Science Foundation. 
(2010) 'Concepts: Between the Subjective and the Objective', in J. Cottingham and P.M.S. Hacker (eds) Mind, Method, and Morality: Essays in Honour of Anthony Kenny, 306-29. Oxford: OUP.

Greco, J. (2003) 'Knowledge as Credit for True Belief', in M. DePaul and L. Zagzebski (eds) Intellectual Virtue: Perspectives from Ethics and Epistemology, I I-34. New York: OUP.

(2007) 'The Nature of Ability and the Purpose of Knowledge', Philosophical Issues, I7/I, $57^{-69}$.

Grimm, S. R. (2015) 'Knowledge, Practical Interests, and Rising Tides', in J. Greco and D. Henderson (eds) Epistemic Evaluation: Purposeful Epistemology, I 7 -37. Oxford: OUP.

Hannon, M. (2013) 'The Practical Origins of Epistemic Contextualism', Erkenn, 78/4, 899-919.

Henderson, D. (20I I) 'Gate-Keeping Contextualism', Episteme, 8/I, 83-98.

Henderson, D. and Horgan, T. (20I5) 'What's the Point?', in J. Greco and D. Henderson (eds) Epistemic Evaluation: Purposeful Epistemology, 87-114. Oxford: OUP.

Kappel, K. (2010) 'On Saying That Someone Knows: Themes From Craig', in A. Haddock, A. Millar and D. Pritchard (eds) Social Epistemology, 69-88. Oxford: OUP.

Kusch, M. (2009) 'Testimony and the Value of Knowledge', in A. Haddock, A. Millar and D. Pritchard (eds) Epistemic Value, 6o-94. Oxford: OUP.

- (201 I) 'Knowledge and Certainties in the Epistemic State of Nature', Episteme, 8/I, 6-23.

(2013) 'Naturalized Epistemology and the Genealogy of Knowledge', in M. Lenz and A. Waldow (eds) Contemporary Perspectives on Early Modern Philosophy: Nature and Norms in Thought, 87-100. Dordrecht and New York: Springer.

Kusch, M. and McKenna, R. (2018) 'The Genealogical Method in Epistemology', Synthese, https://doi.org/I0.1007/si 1229-018-1675-I.

Kvanvig, J. L. (2003) The Value of Knowledge and the Pursuit of Understanding. Cambridge: CUP.

McGrath, M. (2015) 'Two Purposes of Knowledge-Attribution and the Contextualism Debate', in J. Greco and D. Henderson (eds) Epistemic Evaluation: Purposeful Epistemology, I38-57. Oxford: OUP.

McKenna, R. (2014) 'Shifting Targets and Disagreements', Australasian Fournal of Philosophy, 92/4, $725-42$.

(20I5) 'Epistemic Contextualism Defended', Synthese, I92/2, 363-83.

Millgram, E. (2009) 'D'où Venons-Nous ... Que Sommes Nous ... Où Allons-Nous?', in D. Callcut (ed) Reading Bernard Williams, I4 I-65. London and New York: Routledge.

Misak, C. ed. (2007) New Pragmatists. Oxford: OUP.

Moore, A.W. (1993) 'Ineffability and Reflections: An Outline of the Concept of Knowledge', Eur 7 Philosophy, I/3, 285-308.

Price, H. and Macarthur, D. (2007) 'Pragmatism, Quasi-Realism and the Global Challenge', in C. Misak (ed) New Pragmatists, 91-120. Oxford: OUP.

Prinz, J. J. (2002) Furnishing the Mind: Concepts and Their Perceptual Basis. Cambridge, MA: MIT Press.

Pritchard, D. (2012) 'The Genealogy of the Concept of Knowledge and Anti-Luck Virtue Epistemology', in S. Tolksdorf (ed) Conceptions of Knowledge, I59-78. Berlin and Boston: Walter de Gruyter.

Queloz, M. (2017) 'Does Philosophy Have a Vindicatory History? Bernard Williams on the History of Philosophy', Studia Philosophica, 76, I37-52.

(2018a) 'How Genealogies can Affect the Space of Reasons', Synthese, https://doi.org/10.1007/si1229-018-1777-9.

(2018b) 'Williams's Pragmatic Genealogy and Self-Effacing Functionality', Philosophers' Imprint, $\mathrm{I} 8 / \mathrm{I}_{7}, \mathrm{I}-20$.

- (Manuscript), 'From Paradigm-Based Explanation to Pragmatic Genealogy'.

Reynolds, S. L. (2017) Knowledge as Acceptable Testimony. Cambridge: CUP.

Sosa, E. (2007) A Virtue Epistemology: Apt Belief and Reflective Knowledge, vol. I. Oxford: OUP.

Williams, B. (I973) 'Deciding to Believe', in Problems of the Self, i36-5I. Cambridge: CUP.

- (2002) Truth and Truthfulness: An Essay in Genealogy. Princeton: Princeton University Press.

- (2005) Descartes: The Project of Pure Enquiry. London: Routledge.

- (2010) 'Who Needs Ethical Knowledge?', Royal Institute of Philosophy Supplement, 35, 21 3-22.

Williams, M. (2013) 'How Pragmatists can be Local Expressivists', in H. Price (ed) Expressivism,

Pragmatism and Representationalism, I28-44. Cambridge: CUP. 
Williamson, T. (1995) 'Is Knowing a State of Mind?', Mind, I04/415, 533-65. (2000) Knowledge and Its Limits. Oxford: OUP.

(2005) 'Knowledge, Context, and the Agent's Point of View', in G. Preyer and G. Peter (eds) Contextualism in Philosophy: Knoweledge, Meaning, and Truth, 9I-II4. Oxford: OUP.

University of Basel, Switzerland 